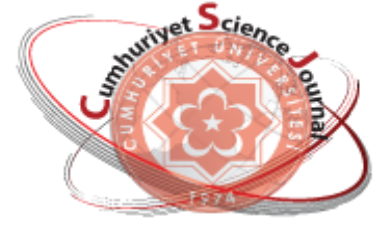

e-ISSN: $2587-246 X$

ISSN: 2587-2680

\section{Cumburiyot Seionee Journal}

esJ

Cumhuriyet Sci. J., Vol.39-3(2018) 720-727

\title{
Intersubband Second Order Nonlinear Transitions in Asymmetric Double Delta-Doped GaAs Structures
}

\author{
Emine ÖZTÜRK
}

Cumhuriyet University, Faculty of Science, Department of Physics, Sivas, TURKEY

Received: 26.07.2018; Accepted: 11.08.2018

http://dx.doi.org/10.17776/csj.448219

\begin{abstract}
In this study, second order harmonic generation (SHG) coefficient in asymmetric double delta doped wells (ADQW) were investigated for a uniform doping distribution model. The electronic properties of GaAs structure with ADQW, such as the potential profile, sub-band energy levels, wave functions and charge densities are calculated by self-consistent the Schrödinger and Poisson equations. According to the parameters used in this study, I have seen that for the doping concentration $1 \times 10^{11} \mathrm{~cm}^{-2}$, SHG peak size in ADQW structure with the intersubband relaxation time $T_{21}=0.5$ ps gives the same peak magnitude value with $T_{21}=$ $0.35 \mathrm{ps}$ for the doping concentration $5 \times 10^{11} \mathrm{~cm}^{-2}$. Also, for the thickness of the donor distribution $1 \mathrm{~nm}$, the peak size value of SHG with $\mathrm{T}_{21}=1$ ps has approximately the same behavior with $\mathrm{T}_{21}=0.35$ ps for the donor distribution thickness $8 \mathrm{~nm}$. The dependence on the structural parameters of the nonlinear transitions in the second order between the sub-bands is more important for the potential variations of the photodetectors and optical modulators. These structures will have an important place in the future research of quantum photo-electronic devices.
\end{abstract}

Keywords: Delta-doping, self-consistent, second order harmonic generation (SHG) coefficient, nonlinear transitions.

\section{Asimetrik Çift Delta Katkılı GaAs Yapılarında Altbantlar Arası İkinci Derece Doğrusal Olmayan Geçişler}

\begin{abstract}
Özet. Bu çalışmada, homojen bir katkılama dağılım modeli için asimetrik çift delta katkılı kuyularda ikinci mertebeden harmonik üretim katsayısı araştırılmıştır. Asimetrik çift delta katkılı kuyulara sahip GaAs yapısının potansiyel profili, alt bant enerji seviyeleri, dalga fonksiyonları ve yük yoğunlukları gibi elektronik özellikleri, Schrödinger ve Poisson denklemlerinin kendi içinde tutarlı hesaplamalarıly belirlenmiştir. Bu çalışmada kullanılan parametrelere göre, $1 \times 10^{11} \mathrm{~cm}^{-2}$ katkı konsantrasyonu için alt bantlar arası gevşeme süresi $\mathrm{T}_{21}=0.5 \mathrm{ps}$ olan yapıdaki ikinci mertebeden harmonik üretim katsayısının pik değerinin, katk1 konsantrasyonu $5 \times 10^{11} \mathrm{~cm}^{-2}$ olan yapıdaki $\mathrm{T}_{21}=0.35 \mathrm{ps}$ süresiyle aynı olduğu görülmektedir. Ayrıca, $1 \mathrm{~nm}$ verici dağılımının kalınlığı için, $\mathrm{T}_{21}=1 \mathrm{ps}$ olan bu harmonik üretim katsayısının pik değeri, verici dağılım kalınlığı $8 \mathrm{~nm}$ için yaklaşık $\mathrm{T}_{21}=0.35$ ps ile aynı davranışa sahiptir. Alt bantlar arasındaki ikinci derecedeki doğrusal olmayan geçişlerin yapısal parametrelerine bağımlılı̆̆ , foto-dedektörlerin ve optik modülatörlerin potansiyel değişimleri için oldukça önemlidir. Kuantum foto-elektronik cihazların gelecekteki araştırmalarında bu yapıların önemli bir yeri olacaktır.
\end{abstract}

Anahtar Kelimeler: Delta katkılama, öz-uyumluluk, ikinci derece harmonic üretim katsayısı, lineer olmayan geçişler. 


\section{INTRODUCTION}

A typical $\delta$-doping semiconductor contains a layer of impurity contained in a few atomic layers of the crystal, and therefore the doping profile in the growth direction is commonly used as an n-type dopant in GaAs growth using MBE. When Si donors are localized in an atomic plane during epitaxial growth, an ionized donor layer brings the electron into a V-shaped potential well that defines a delta-doped plane in the vertical direction and leads to the formation of a semitwo-dimensional electron (2DEG). The eigenvalues of this 2DEG depend on the shape of the field-charge potential. The electronic structure of the system is calculated by solving the Schrödinger and Poisson equations by selfconsistent [1-3].

To produce $\delta$-doped semiconductor devices with high mobility, some authors have focused on developing doping and material growth techniques [4]. An alternative way to increase electron mobility in recently proposed $\delta$-doped semiconductors is to form a structure with double or triple $\delta$-layers [5-7]. The increase in mobility and concentrations in these structures is partly due to the distribution of more carriers in the center of two $\delta$-doped GaAs wells. In these structures, the carrier transport is spatially separated from the ionized impure scattering centers, and consequently the electron mobility increases two to five times over a single $\delta$-doped case [5]. Thus, double layer structures open up possibilities for higher electron mobility than single layer systems.

The nonlinear optical properties of intersubband transitions are of great interest due to the strong quantum confinement effect, the large values of dipole transition matrix elements and the possibility of achieving resonance conditions. For the optical properties of low-dimensional semiconductor systems, linear and non-linear intersubband optical transitions have attracted more attention in theoretical and experimental investigations [8-13]. Among the various nonlinear processes, attention is drawn to the second harmonic generation [14-17], which requires the construction of the asymmetric quantum well (AQW).

In this study, for coupled $\delta$-doped asymmetric double quantum wells (ADQW) I investigate the intersubband second order nonlinear transitions within n-type $\delta$-doped GaAs layer for the (1-2) transition. The effects of the structure parameters on the electronic states and the second harmonic generation (SHG) susceptibility of ADQW are studied.

\section{THEORY}

At effective-mass approximation, to obtain the sub-band structure (the confining potential, the density profile, the sub-band energies, the electron concentrations and the Fermi energy) I have solved self-consistently the Schrödinger and Poisson equations for the uniform distribution. A flow chart of the self-consistent calculation is shown in Fig. 1 and further details about the calculation by solving the Schrödinger and the Poisson equations self-consistently can be found in Ref. [18].

After the effective $\delta$-potential profile, the energy levels and their corresponding wave functions are obtained, the optical properties of the ADQW can be calculated by the density matrix approach.

In this study, I have interested SHG in a two-level system, considering the filled states in ADQW. By using the compact density matrix approach in Refs. [15, 19], SHG susceptibility is derived, and it is given by. 


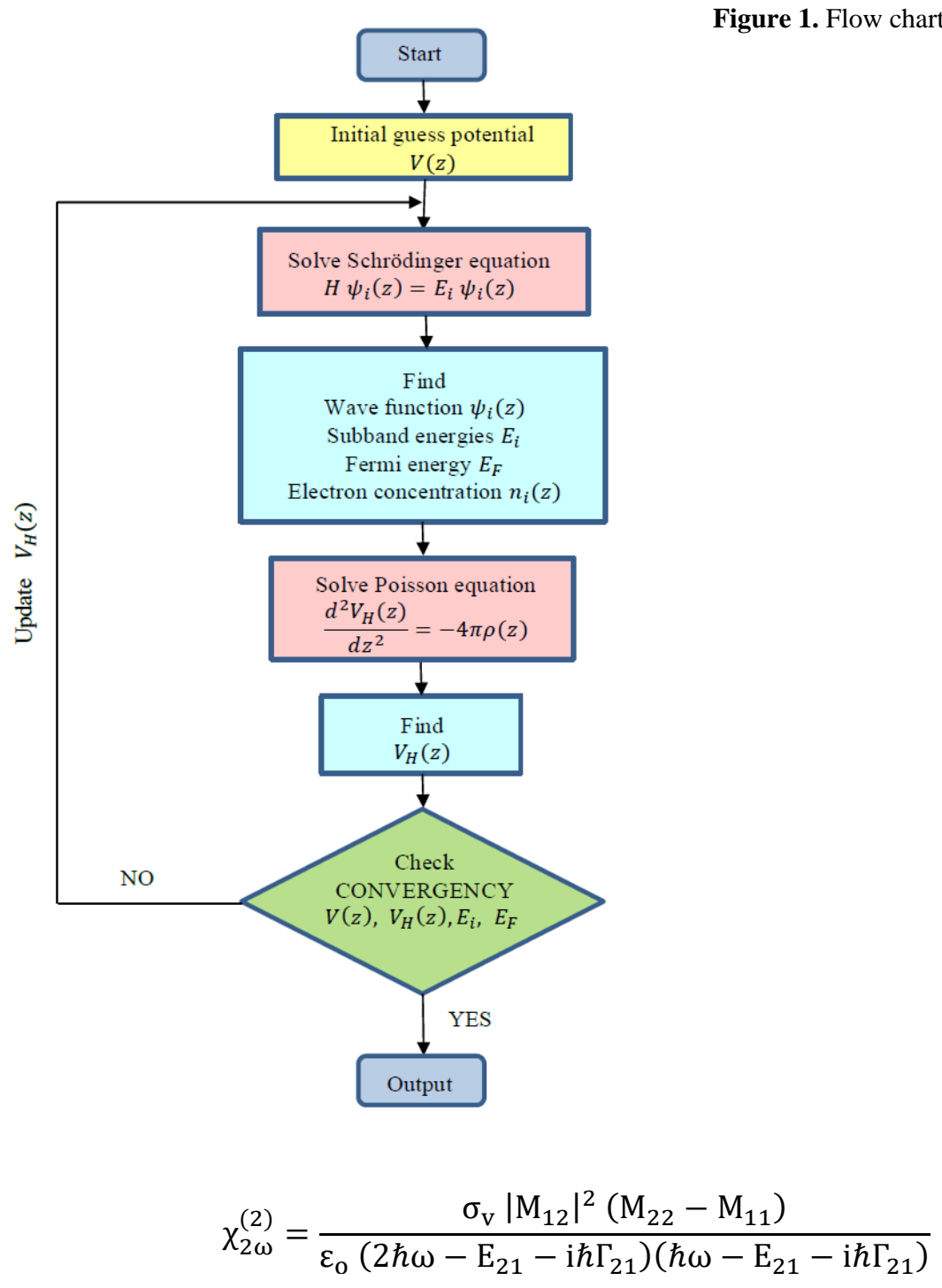

where only the near-resonant term at $2 \hbar \omega \cong$ $E_{21}$ is considered. $\Gamma_{21}$ is the relaxation rate for states 1 and 2, $\omega$ is the frequency of the incident radiation, $\varepsilon_{0}$ is the electrical permittivity of vacuum, $\mathrm{E}_{21}=\mathrm{E}_{2}-\mathrm{E}_{1}$ and $\mathrm{M}_{\mathrm{if}}=<\Psi_{\mathrm{i}}|\mathrm{e} \mathrm{z}| \Psi_{\mathrm{f}}>$

$$
\sigma_{v}=\frac{m^{*} k_{B} T}{L_{e f f} \pi \hbar^{2}} \ln \left\{\frac{1+e^{\frac{\left(E_{F_{F}}-E_{1}\right)}{k_{B} T}}}{1+e^{\frac{\left(E_{F_{2}}-E_{2}\right)}{k_{B} T}}}\right\}
$$

where $E_{F}$ is the Fermi energy, $L_{e f f}$ is the effective extension of electrons.

\section{RESULTS AND DISCUSSION}

For numerical calculations, I have taken $m^{*}=$ $0.0665 m_{0}\left(m_{0}\right.$ is the free electron mass), the separation between the adjacent two doping layers is $\quad\left\{b^{\mathrm{L}}+\mathrm{b}^{\mathrm{R}}+\left(\mathrm{d}_{\mathrm{L}}+\mathrm{d}_{\mathrm{R}}\right) / 2\right\}=10 \mathrm{~nm}, \quad$ the thickness of the donor distribution for the right layer is $d_{R}=4 \mathrm{~nm}$, the doping concentration for the right layer is $\mathrm{Nd}^{\mathrm{R}}=3 \times 10^{11} \mathrm{~cm}^{-2}, \mathrm{~L}_{\text {eff }}=$ $60 \mathrm{~nm}, \mathrm{~T}=300 \mathrm{~K}$, the intersubband relaxation time is $\mathrm{T}_{21}=1 / \Gamma_{21}=0.5 \mathrm{ps}$ and $1 \mathrm{ps}$. 
Fig. 2 shows a schematic representation of the potential profile of $A D Q W$. The asymmetry of the effective potential can be controlled by changing the structural parameters, and this adjustable asymmetry is important to optimize SHG susceptibility. For different doping concentrations and doping thicknesses, the energy difference between the ground and second sub-band, Fermi energy and the sub-band electron concentrations is given in Table 1.

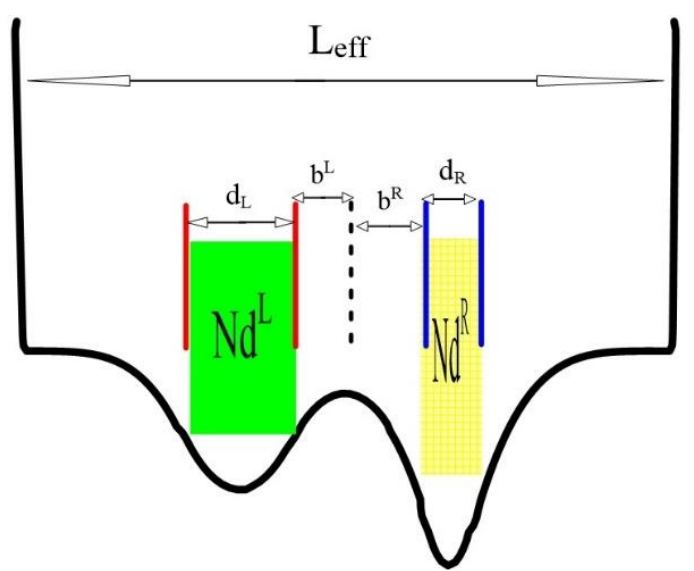

Figure 2. The schematic representation of the potential profile of

ADQW.

Table 1. For different doping concentrations and doping thicknesses, the energy difference between the ground and second sub-band, Fermi energy and the sub-band electron concentrations for ADQW.

\begin{tabular}{cccccc}
\hline $\begin{array}{c}\mathrm{d}_{\mathrm{L}} \\
(\mathrm{nm})\end{array}$ & $\begin{array}{c}\mathrm{Nd}^{\mathrm{L}} \\
\left(\mathrm{x} 10^{11} \mathrm{~cm}^{-2}\right.\end{array}$ & $\begin{array}{c}\mathrm{E}_{21} \\
(\mathrm{meV})\end{array}$ & $\begin{array}{c}\mathrm{E}_{\mathrm{F}} \\
(\mathrm{meV})\end{array}$ & $\begin{array}{c}\mathrm{n}_{1} \\
\left(\times 10^{11} \mathrm{~cm}^{-2}\right)\end{array}$ & $\begin{array}{c}\mathrm{n}_{2} \\
\left(\times 10^{11} \mathrm{~cm}^{-2}\right)\end{array}$ \\
\hline 4 & 1 & 8.79 & 6.96 & 3.23 & 0.77 \\
4 & 3 & 10.03 & 8.99 & 4.40 & 1.60 \\
4 & 5 & 11.08 & 11.22 & 5.55 & 2.45 \\
1 & 3 & 10.10 & 9.63 & 4.41 & 1.59 \\
4 & 3 & 10.03 & 8.99 & 4.40 & 1.60 \\
8 & 3 & 9.96 & 8.09 & 4.39 & 1.61 \\
\hline
\end{tabular}

For different doping concentrations, Fig. 3 (a-b) display the potential profile, the ground and the second sub-band energies with their squared envelope wave functions. The dashed curves in this figure are for symmetrical DQW. At high doping concentrations, an increasing charge density in the $\delta$-doped layer leads to more band bending and a deeper quantum well. This feature could be of use in controlling the confinement of carriers in devices using this type of doping. Since the donor impurities in the left well (LW) are localized in a narrower range with respect to the right well (RW), the effective potential is narrower and deeper, the band bending is greater, and the squared wave functions of the confinement sub-band energies are more limited in the well (see Fig. 3b). However, the situation for Fig. 3a is exactly the opposite. Thus, it can be seen that the donor concentration influences the performance of the device, such as the limitation, and the values of the obtained sub-band energies depend on the different donor concentrations. These configurations are important for the linear and nonlinear optical response of the structure. So,
I can say that the depth of the QW affects the restraint and localization. 

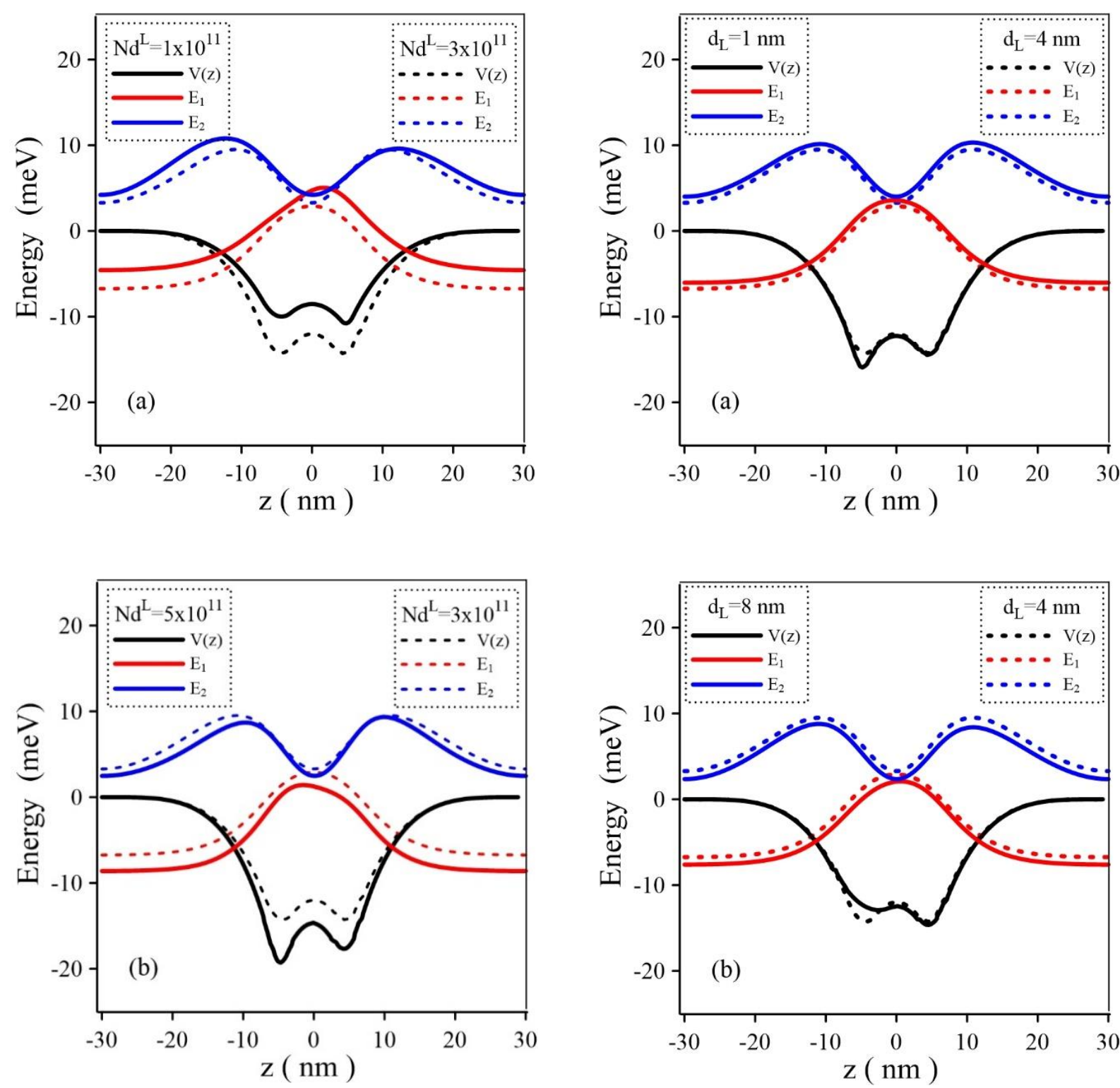

Figure 3. The potential profile (the black curves) and the ground (the red curves) and the second (the blue curves) subband energies with their squared envelope wave functions for a) $\mathrm{Nd}^{\mathrm{L}}=1 \times 10^{11} \mathrm{~cm}^{-2}$, b) $\mathrm{Nd}^{\mathrm{L}}=3 \times 10^{11} \mathrm{~cm}^{-2}$. The dashed curves are for symmetric DQW $\left(\mathrm{Nd}^{\mathrm{R}}=\mathrm{Nd}^{\mathrm{L}}\right.$ and $\left.\mathrm{d}_{\mathrm{R}}=\mathrm{d}_{\mathrm{L}}\right)$.

In Fig. 4 (a-b), the potential profile, the ground and the second sub-band energies together with the squared envelope wave functions are given for different donor thicknesses. The depth of the active potential decreases slightly with increasing the thickness of the $\delta$-doped layer, and the squared wave functions of the confinement sub-band energies expand slightly. For $d_{L}=1 \mathrm{~nm}$, the effective potential profile is higher than for $\mathrm{d}_{\mathrm{L}}=$

Figure 4. The potential profile (the black curves) and the ground (the red curves) and the second (the blue curves) subband energies with their squared envelope wave functions for a) $d_{L}=1 \mathrm{~nm}$, b) $d_{L}=8 \mathrm{~nm}$. The dashed curves are for symmetric DQW $\left(\mathrm{d}_{\mathrm{R}}=\mathrm{d}_{\mathrm{L}}\right.$ and $\left.\mathrm{Nd}^{\mathrm{R}}=\mathrm{Nd}^{\mathrm{L}}\right)$.

The electronic density profiles are shown for different doping concentrations and thicknesses in Fig. 5 (a-b). As seen in Fig. 5a, the electron density profiles for higher doping concentrations are more localized around the $\delta$-doped GaAs layer and give a big peak. As the thickness of the $\delta$ doped layer changes, the intensity profiles vary slightly very little (see Fig. 5b). $8 \mathrm{~nm}$. 

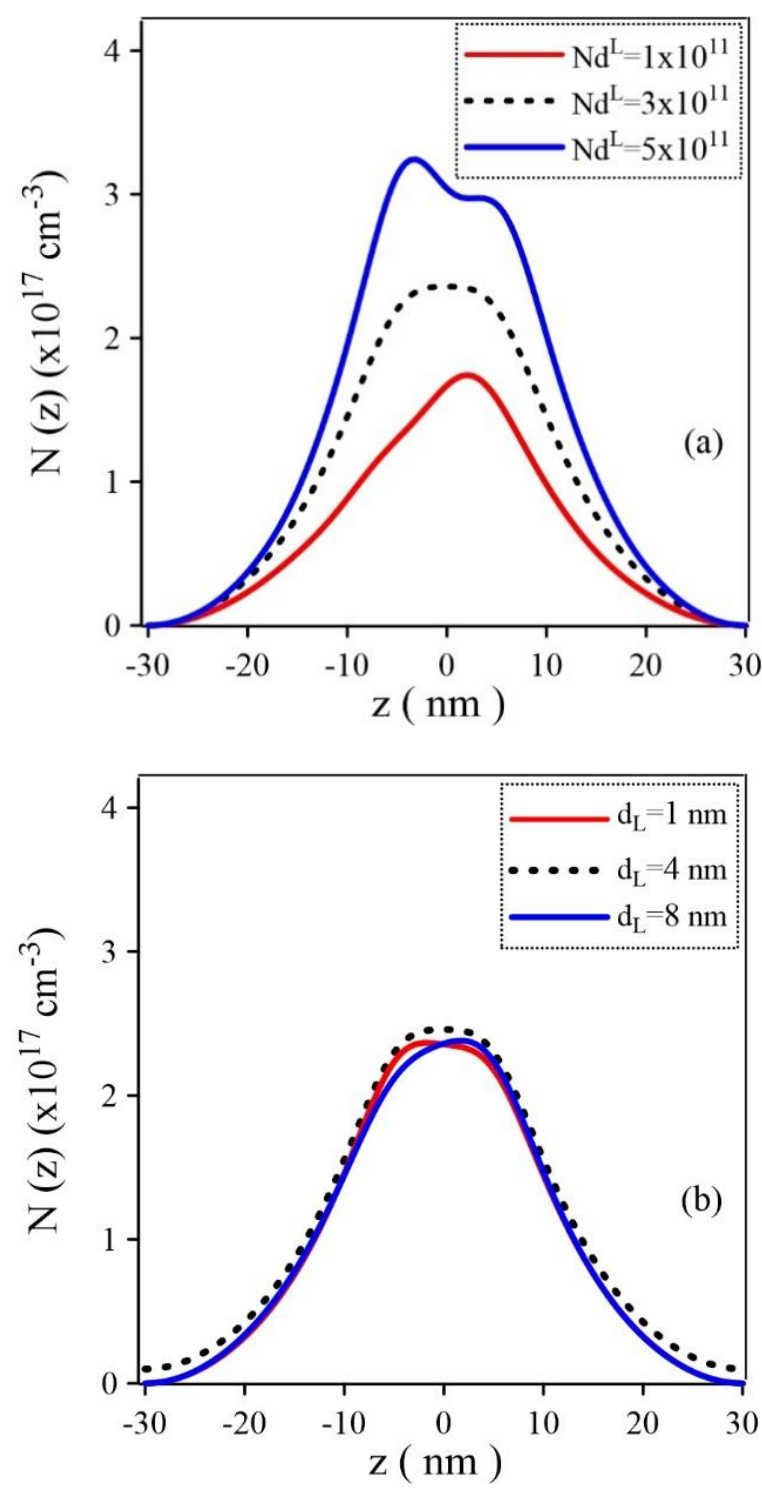

Figure 5. The charge density profiles for different a) $\mathrm{Nd}^{\mathrm{L}}$ values, b) $d_{L}$ values. The dashed curves are for symmetric DQW.

For two different the intersubband relaxation time, Fig. 6 (a-b) represents SHG susceptibility as a function of incident photon energy for different doping concentrations and thicknesses. SHG susceptibility depends on the energy difference between two electronic states and on the matrix elements of electric dipole moment. The changing values of the structural parameters vary both the peak values and the position of SHG susceptibility. The former depends on the intersubband energy levels separation and the last is determined fundamentally by the wave-function behavior. This behavior can be explained in that with the increase of $\mathrm{Nd}^{\mathrm{L}}$ the quantum- confinement effect to the electron increases quickly, therefore, the energy levels of this narrow system become far from one another, i.e. the energy intervals are enhanced, and as a result, the peak of SHG susceptibility appears at the highenergy direction, i.e. suffers a blue-shift. It is easily seen from Figure $6 a$ that as the doping concentration increases, the resonant peak of SHG susceptibility decreases and shifts to blue. By increasing $d_{L}$, the resonant peak of SHG susceptibility increases and slightly shifts to red (see Fig. 6b). The peak of SHG susceptibility always decreases as the depth of the confined potential increases. The single peak related to two-photon resonance is split into two peaks related to two single-photon resonances. Since the intrasubband dipole matrix elements $\left(\mathrm{M}_{\mathrm{ii}}\right)$ there is no for symmetric DQW, SHG susceptibility coefficient vanishes. As expected, for $\mathrm{T}_{21}=$ 0.5 ps the peaks of SHG susceptibility are smaller than for $\mathrm{T}_{21}=1 \mathrm{ps}$. There is no shift at the resonant peak location with intersubband relaxation time. According to the parameters used in this study, I have obtained that the peak magnitude value of SHG susceptibility in ADQW with $\mathrm{T}_{21}=0.5 \mathrm{ps}$ for $\mathrm{Nd}^{\mathrm{L}}=1 \times 10^{11} \mathrm{~cm}^{-2}$ has approximately the same behavior as ADQW system with $\mathrm{T}_{21}=1.45 \mathrm{ps}$ for $\mathrm{Nd}^{\mathrm{L}}=$ $5 \times 10^{11} \mathrm{~cm}^{-2}$. Also, for $\mathrm{d}_{\mathrm{L}}=1 \mathrm{~nm}$ the structure with $\mathrm{T}_{21}=1$ ps gives the same peak size value with $\mathrm{T}_{21}=0.35 \mathrm{ps}$ for $\mathrm{d}_{\mathrm{L}}=8 \mathrm{~nm}$. Thus, the intersubband relaxation time can be used as a fitting parameter in the calculations to obtain the same peak valuation of SHG susceptibility in ADQW structure. The results obtained show that the structure parameters (especially the doping concentration) of ADQW significantly influence SHG susceptibility. This behavior in SHG susceptibility gives a new degree of freedom in areas of interest for device applications. 

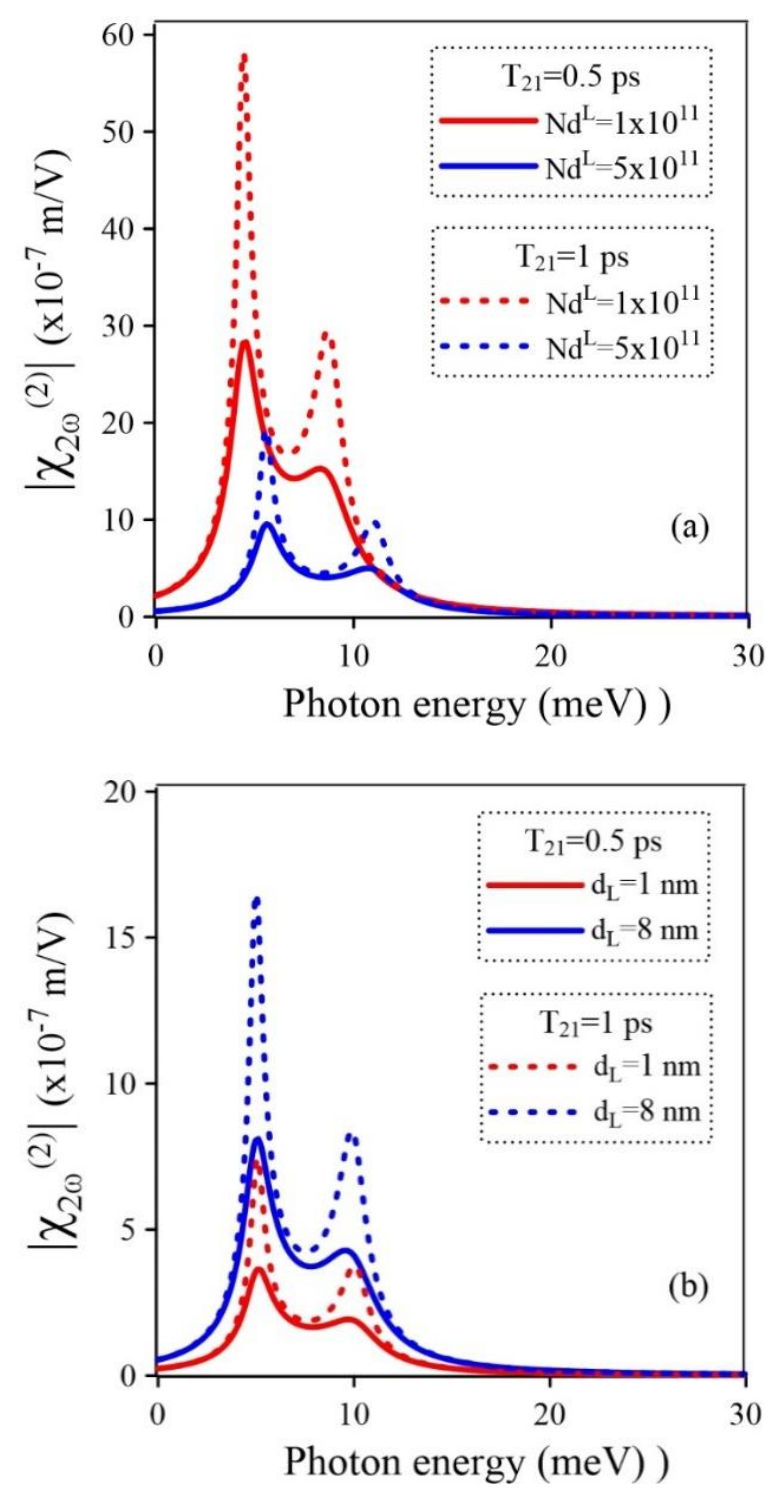

Figure 6. For two different the intersubband relaxation time, SHG susceptibility as a function of incident photon energy $\hbar \omega$ for different a) $\mathrm{Nd}^{\mathrm{L}}$ values, b) $\mathrm{d}_{\mathrm{L}}$ values.

\section{CONCLUSIONS}

In this study, SHG susceptibility coefficient of asymmetric double $\delta$-doped GaAs structure was investigated depending on the doping concentration and thickness for a uniform doping distribution model. The electronic structure is calculated by continuously solving the Schrödinger and Poisson equations. It has been shown that the electronic properties are strongly dependent on doping concentrations, both $\mathrm{Nd}^{\mathrm{L}}$ and $d_{L}$ can be used as the adjustable parameters for these systems. Based on these results, SHG susceptibility can be relatively easily controlled by the doping concentration and thickness. These theoretical results can take place in experimental studies and provide some kind of approximate modeling for the practical application such as optoelectronics devices and optical communication.

Devices with $\delta$-doped semiconducting structures have received a lot of attention recently due to the potential technological applications in electronic and photonic devices. For this reason, such $\delta$ doped semiconductor structures are important for the devices such as high-power FETs and various infrared optical modulators based on the intersubband transition of electrons.

\section{Acknowledgments}

This work is supported by the Scientific Research Project Fund of Cumhuriyet University under the project number F-519.

\section{REFERENCES}

[1]. Degani M.H., Electron energy levels in a delta-doped layer in GaAs, Phys. Rev. B 44 (1991) 5580-5584

[2]. Ozturk E., Optical intersubband transitions in double $\mathrm{Si}$-doped GaAs under an applied magnetic field, Superlatt. Microstruct. 46 (2009) 752-759

[3]. Gaggero-Sager L.M., Naumis G.G., Munoz-Hernandez M.A., Montiel-Palma V., Self- consistent calculation of transport properties in $\mathrm{Si} \delta$-doped GaAs quantum wells as a function of the temperature, Physica B 405 (2010) 4267-4270

[4]. Schubert E.F., Fischer A., Ploog K., The delta-doped field-effect transistor, IEEE Trans. Electron Devices 33 (1986) 625-632

[5]. Zheng X., Carns T.K., Wang K.L., Wu B., Electron mobility enhancement from coupled wells in delta-doped GaAs, Appl. Phys. Lett. 62 (1993) 504-506

[6]. Hai G.Q., Studart N., Peeters F.M., Electron mobility in two coupled delta layers, Phys. Rev. B 52 (1995) 11273-11276

[7]. Chen L.Y., Cheng S.Y., Chen T.P., Chu K.Y., Tsai T.H., Liu Y.C., Liao X.D., Liu 
W.C., On an InGaP/InGaAs double channel pseudomorphic high electron mobility transistor with graded triple $\delta$-doped sheets, IEEE Trans. Electron Devices, 55 (2008) 3310-3318

[8]. Karabulut I., Baskoutas S., Linear and nonlinear optical absorption coefficients and refractive index changes in spherical quantum dots: Effects of impurities, electric field, size, and optical intensity, J. Appl. Phys. 103 (2008) 073512-073516

[9]. Ozturk E., Ozdemir Y., Linear and nonlinear intersubband optical absorption coefficient and refractive index change in $n$ type d-doped GaAs structure, Opt. Commun. 294 (2013) 361-367

[10]. Restrepo R.L., Morales A.L., MartinezOrozco J.C., Baghramyan H.M., Barseghyan M.G., Mora-Ramos M.E., Duque C.A., Impurity-related nonlinear optical properties in delta-doped quantum rings: Electric field effects, Physica B 453 (2014) 140-145

[11]. Oubram O., Rodriguez-Vargas I., Martinez-Orozco J. C., Refractive index changes in n-type delta-doped GaAs under hydrostatic pressure, Revista Mexicana de Fisica 60 (2014) 161-167.

[12]. Kasapoglu E., Yesilgul U., Ungan F., Sokmen I., Sari H., The effect of the intense laser field on the electronic states and optical properties of n-type double $\delta$-doped GaAs quantum wells, Optical Materials 64 (2017) 82-87
[13]. Ozturk E., Nonlinear transitions in single, double, and triple $\delta$-doped GaAs structures, Romanian Journal of Physics 62 (2017) 603-612

[14]. Tsang L., Chuang S.L., Lee S.M., Secondorder nonlinear optical susceptibility of a quantum well with an applied electric field, Phys. Rev. B 41 (1990) 5942-5951

[15]. Karabulut I., Atav U. , Safak H., Tomak M., Second harmonic generation in an asymmetric rectangular quantum well under hydrostatic pressure, Physica B 393 (2007) 133-138

[16]. Martinez-Orozco J. C., Mora-Ramos M. E., Duque C. A., Nonlinear optical rectification and second and third harmonic generation in GaAs $\delta$-FETsystems under hydrostatic pressure, J. Lumin., 132 (2012) 449-456

[17]. Martinez-Orozco J. C., Rojas-Briseno J. G., Rodriguez-Magdaleno K. A., Rodriguez-Vargas I., Mora-Ramos M. E., Restrepo R. L., Ungan F., Kasapoglu E., Duque C. A., Effect of the magnetic field on the nonlinear optical rectification and second and third harmonic generation in double $\delta$-doped GaAs quantum wells, Physica B 525 (2017) 30-35

[18]. Ozturk E., Sokmen I., Intersubband transitions for single, double and triple $\mathrm{Si} \delta$ doped GaAs layers, Phys. D: Appl. Phys. 36 (2003) 2457-2464

[19]. Tsang L., Ahn D., Chuang S.L., Electric field control of optical second harmonic generation in a quantum well, Appl. Phys. Lett. 52 (1988) 697-699 